\title{
O SENTIMENTO DO PACIENTE FRENTE AO CANCELAMENTO DA CIRURGIA
}

\author{
Fernanda Aparecida Silva ${ }^{1}$ \\ Poliana Turino da Silva Monteiro² \\ Ana Paula da Silva ${ }^{3}$ \\ Caroline Batalha Cé ${ }^{4}$ \\ Ana Lucia De Faria ${ }^{5}$ \\ Eliana Fatima de Almeida Nascimento ${ }^{6}$ \\ Teresa Celia de Mattos Moraes dos Santos ${ }^{7}$
}

Resumo: O paciente, frente ao cancelamento da cirurgia, pode apresentar sentimentos: tristeza, agressividade, revolta, e perder a confiança da equipe cirúrgica. Objetivo: Identificar o sentimento do paciente internado frente ao cancelamento de sua cirurgia. Método: Pesquisa descritiva e qualiquantitativa. A coleta de dados ocorreu após aprovação do Comitê de Ética sob o $n^{0}$ 45/11, com 20 pacientes internados em um hospital do vale do Paraíba paulista. Resultados: Predominou:80\% do sexo masculino, $30 \%$ de 51 a 60 anos. Principal causa cancelamento: 35\% material, 10\% vaga na Unidade de Terapia Intensiva (UTI), e 55\% médicos, exames, vaga no centro cirúrgico ou infecção. Os sentimentos foram agrupados em quatro categorias: tristeza; estresse; conformismo e sentimentos variados. Conclusão: $O$ perfil predominante dos pacientes foi de homens, entre 51 a 60 anos. A principal causa do cancelamento foi a falta de material; o sentimento de maior destaque foi a tristeza.

Palavras-chave: Sentimento; Cancelamento; Paciente; Dietas hospitalares; Temperatura dos alimentos; Qualidade dos alimentos.

\footnotetext{
${ }^{1}$ Curso de Enfermagem/Universidade de Taubaté, Brasil. E-mail: fernandynhaaparecida@gmail.com.

${ }^{2}$ Curso de Enfermagem/Universidade de Taubaté, Brasil. E-mail: polianatsm94@hotmail.com.

${ }^{3}$ Curso de Enfermagem/Universidade de Taubaté, Brasil. E-mail: anapaulaleona@hotmail.com.

${ }^{4}$ Curso de Enfermagem/Universidade de Taubaté, Brasil. E-mail: carolbatalhace@hotmail.com.

${ }^{5}$ Curso de Enfermagem/Universidade de Taubaté, Brasil. E-mail: anadinda2002@yahoo.com.br.

${ }^{6}$ Curso de Enfermagem/Universidade de Taubaté, Brasil. E-mail: efanascimento@yahoo.com.br.

${ }^{7}$ Curso de Enfermagem/Universidade de Taubaté, Brasil. E-mail: teresacelia@terra.com.br.
} 